\title{
Prediction of Sovereign Credit Risk Rating Using Sensing Technology
}

\author{
Chen-Ying Yen, ${ }^{1}$ Yi-Ling Ju, ${ }^{2}$ Shih-Fu Sung, ${ }^{3 *}$ Yu-Lung Wu, ${ }^{3}$ and En-Der $\mathrm{Su}^{4}$ \\ ${ }^{1}$ Department of Hospitality, Meiho University, \\ No. 23, Pingguang Rd., Neipu Township, Pingtung County 912009, Taiwan \\ ${ }^{2}$ Department of Information Engineering, I-Shou University, \\ No. 1, Sec. 1, Syuecheng Rd., Dashu District, Kaohsiung City 84001, Taiwan \\ ${ }^{3}$ Department of Information Management, I-Shou University, \\ No. 1, Sec. 1, Syuecheng Rd., Dashu District, Kaohsiung City 84001, Taiwan \\ ${ }^{4}$ Department of Risk Management and Insurance, National Kaohsiung University of Science and Technology, \\ No. 1, University Rd., Yanchao District, Kaohsiung City 824, Taiwan
}

(Received December 31, 2020; accepted August 24, 2021)

Keywords: Internet of Things (IoT), CDS spread, sovereign credit rating

In recent years, the study and application of sensor technology have expanded from the industrial to the commercial, financial, and even medical fields. In Taiwan, many studies link sensor technology and the Internet of Things (IoT) with commercial finance, and research on their applications to commercial financial warning or company management is being conducted. The cross-discipline integration of IoT and finance has advanced through the diversification of IoT, and that is why the financial service industry will use IoT as a service platform to provide cross-disciplinary integration services. After exchanging and collecting information by using sensors and handheld devices, it helps to develop new business models such as supply chain financial services to share and manage networks. This enables the financial industry to have a more comprehensive and different understanding of customers and enterprises, which can help the financial industry explore different business opportunities. The aim of this study is to use IoT technology to perform real-time analysis of treasury bill big data and to apply the principles behind sensing to predict and analyze the probability of international defaults in order to reduce investment risks and estimate the credit default swap (CDS) spread. We will then compare the results for the macroeconomic variables with the results of relevant analyses on indicators. The results of the correlation analysis show that the CDS spread and the ratio of the current account balance $(\mathrm{CAB})$ to the gross domestic product have a negative correlation with the gross domestic product growth (GDPG) rate. It has a positive correlation with the inflation rate (INF), the ratio of government debt to gross domestic product (DEBT), and the industrial production index annual growth rate (IPIG). Therefore, the result and the rating-implied expected loss (RIEL) are the same as those in the relevant analysis results of these five macroeconomic indicators. It was also found that IoT technology can be used in the real-time analysis of large-scale treasury bill data, and the principle of sensing can be applied to predict and analyze the accuracy of international defaults.

*Corresponding author: e-mail: poem5203@gmail.com https://doi.org/10.18494/SAM.2021.3244 


\section{Introduction}

Sensing technology is used to mark object-related information with a barcode or a twodimensional barcode and provides a scanning sensor to read an object's information (barcode) to read the economic data of various countries. In radio-frequency identification (RFID) technology, sensors emit radio waves to activate the RFID tag within the effective sensing range; the chip of the tag is activated by the radio waves from the sensor and responds to the sensor. The application-related development covers a variety of innovative application integration services, such as wearable devices, smart homes, energy saving and carbon reduction, smart businesses, smart grids, and smart transportation, as well as various big data application technologies derived from a large amount of information by the Internet of Things (IoT). The big data generated by the IoT usually contains information such as time, location, environment, and behavior. Through the storage, mining, and in-depth analysis of big data, the natural and behavioral attributes of customers can be elucidated, providing financial institutions with various decision-making references to perform comprehensive analysis, processing, and judgment. Then, relevant financial services can be offered. Therefore, IoT finance can also be regarded as an extension of financial information. The IoT has wisdom and communication capabilities, and can perform historical tracking, control the present, and even predict the future. Its impact on traditional industries will far exceed the impact of the Internet. Online finance comprises a combination of information flow and capital flow. After the emergence of the IoT, Internet finance and IoT technology have enabled capital flow, information flow, and physical flow to be combined.

The advent of the digital technology era has surpassed traditional limits and provided unprecedented powerful information processing capabilities to solve difficult or even previously unsolvable problems in various fields such as medical treatment, finance, technology, energy, agriculture, manufacturing, logistics, and transportation. It will have a significant impact on the industry's paradigm shift in information especially in the areas of simulation, forecasting, and artificial technology.

From the Asian financial crisis in 1998 and the financial crisis of 2007-2008 to the European debt crisis in 2009, many countries have accumulated debts in the past 20 years. As the Federal Reserve System continues to increase credit costs, it has become the major worry for these debtor countries. One of the reasons for the European debt crisis in 2009 was that the three global credit rating agencies downgraded Greece's sovereign rating, which caused the Greek stock market to tumble and the sovereign debt became as high as 300 billion euros, indicating that the importance of national credit ratings cannot be ignored.

Debt defaults occur every year throughout the world; they may be corporate debt defaults or sovereign debt defaults. Sovereign default events occur every year, for example, from Belize in 2006, Ecuador and Seychelles in 2008, and Ukraine in 2015 (Table 1), which indicates the existence of credit default risk. In this study, we intend to use IoT technology for real-time analysis of big data related to the sovereign treasury and to apply the principle of sensing to predict and analyze the probability of international defaults to reduce investment risk.

After the subprime mortgage crisis in the United States, global competition became increasingly fierce. To enhance industrial competitiveness, mastering emerging core 
Table 1

Debt defaulting countries in 2006-2015 (compiled from Moody's 2016 Annual Report).

\begin{tabular}{|c|c|c|c|c|c|c|c|c|c|c|}
\hline & 2006 & 2007 & 2008 & 2009 & 2010 & 2011 & 2012 & 2013 & 2014 & 2015 \\
\hline $\begin{array}{l}\text { Defaulting } \\
\text { countries }\end{array}$ & Belize & - & $\begin{array}{l}\text { Ecuador } \\
\text { Seychelles }\end{array}$ & - & Jamaica & $\begin{array}{c}\text { Côte } \\
\text { d'Ivoire } \\
\text { St. Kitts } \\
\text { and } \\
\text { Nevis }\end{array}$ & $\begin{array}{l}\text { Belize } \\
\text { Greece }\end{array}$ & $\begin{array}{c}\text { St. Kitts } \\
\text { and } \\
\text { Nevis } \\
\text { Grenada } \\
\text { Cyprus } \\
\text { Jamaica }\end{array}$ & Argentina & Ukraine \\
\hline
\end{tabular}

technologies and developing the IoT have become key industrial strategies for all countries. In particular, declining birthrates have curbed the growth of the domestic demand market and reduced labor supply in various countries, creating a productivity crisis. The application of the IoT to improve productivity has become a solution to the shortage of labor. ${ }^{(1)}$

Sensors can also be used to determine the prediction mechanism in management science and to set a certain interval value on the sensing element as the timing value. If this value is exceeded, an early warning mechanism is activated, and a warning is given through the terminal, the IoT, and the program to reduce unnecessary losses. Conversely, the change in the value can also be used to raise an alert to market opportunities. Of course, this predicted value must have an index of dimensions. IoT technology will be used to analyze large-scale treasury bills in real time and the principle of sensing to predict and analyze the probability of default (PD) in various countries in order to reduce investment risks and estimate credit default swap (CDS) spreads.

In this study, we apply sensing technology and the IoT to analyze the macroeconomic data of various countries in real time. According to the motivation mentioned above, a country's credit status and the direct judgment of credit status are based on the following three global credit rating agencies: Moody's Corporation, S\&P Corporation, and Fitch Corporation. The credit rating agencies make a credit judgment on the operation of the company or the country, and then make their judgment public so that investors and decision makers can refer to it to decide whether to invest. Therefore, in this study, the sensing technology and IoT of real-time analysis are used as indicators of the Republic of China (ROC) Government's New Southbound Policy.

\section{Theoretical Background}

\subsection{Sensor network}

The main function of the sensor network is to collect data at experimental sites, where the scope of the experiment can be large or small. The sensor can be used to collect various data, such as temperature, humidity, sound, vibration, and pressure, in accordance with the needs of the experiment. A sensor network is a network composed of a group of sensors. The collected data can be sent back to the data processing center through the sensor network. Therefore, a device similar to a base station, relay, or router is required to consolidate the data collected in an area. The sensor can communicate through a wired or a wireless network. The power supply can be a conventional power cord or a battery; for example, the sensors built into a building can usually be used with a wired network to match the power supply or with a network cable that can 
simultaneously provide power [namely, Power over Ethernet (PoE) technology]. In a large-scale environment where it is difficult to build a network and power supply, wireless network communication and battery-powered sensors may be used.

\subsection{IoT and commercial applications}

The continuous development of information and communication technology has created an abundance of IoT business opportunities. In the era of the IoT, there will be a gradual shift from manual data recording to software or sensor methods, and traditional storage of data on paper will be converted into storage of digital data. The economic activities on production and consumption can be managed more accurately and efficiently. Even for the future application to big data, AI, and other technological models, its management efficiency is likely to improve further. ${ }^{(2)}$ IoT is currently a popular topic. Although the technology is not brand new, its limitless possibilities have gradually broken down the walls of the current business model. The IoT has opened up an information dialogue between "objects and objects", creating smarter and more appealing products and services. The IoT has accumulated the energy of big data, giving rise to new operational management and strategic challenges. Related IoT technologies, including hardware and software, are gradually being developed. Professional authorities, such as Ashton Kevin, put forward the concept of the IoT in his papers; therefore, the IoT is regarded as an important development direction by many countries, and many companies have begun to study and develop this field. Service innovation is valued by many companies and organizations, and they are actively developing innovative service models. Through the results of the IoT technology analysis on service innovation, it is found that the application of IoT-related hardware and technologies on the customer service interface can effectively improve the speed and quality of services. Then, by collecting relevant data on operation to create new value for enterprises, organizations, smart homes, ${ }^{(3)}$ and smart cities to smart earth, the disruptive innovation of the IoT will bring changes for everyone. ${ }^{(4)}$

The provision of Internet mobile insurance claims and other services by Taiwanese insurance companies has become increasingly common. In InsurTech, the strengthening of insurance IoT seems to be the key to the success of the insurance industry. The convenience of IoT insurance marketing has been positive; the customer has a higher willingness to apply for online insurance. ${ }^{(5)}$ With the creation of a connection between the IoT and the insurance industry, as well as the introduction of IoT-related applications in the property and life insurance industry, the connection between the IoT and big data is also another topic that should be explored. It can be used as Taiwan's insurance industry on the IoT reference for development in the future. ${ }^{(6)}$

The aim of this research is to explore the factors influencing enterprise risk management and the auditing mechanism of internal control in the IoT environment. Applying a qualitative research approach and following Gowin Vee's research strategy, ${ }^{(7)}$ firstly, we reviewed the relevant literature and used the Delphi expert assessment method ${ }^{(8)}$ to identify risk factors as well as audit items in the IoT environment. Secondly, in accordance with the nature of eight types of intersecting risks and the internal control framework of COSO 2013, ${ }^{(9)}$ we constructed the three lines of defense in effective risk management and the internal control mechanism 
referring to the evaluation criteria of Capability Maturity Model Integration (CMMI). Lastly, we conducted an empirical case study of three enterprises to verify whether the risk factors and auditing mechanism can be effectively used for internal risk control assessment within the corporation. The audit mechanism established in this study and the empirical methodology of case study can be referenced by academia for enhancing the knowledge of qualitative research. ${ }^{(10)}$ To support the innovative development of the IoT, advanced countries have already launched IoT study projects to accelerate the digital transformation of industries and promote the IoT as one of the most important forces driving the development of the technology industry. The EU research and development plan aims to collect popular developed technology, implement practices, tests, verification models, and industrialization mechanisms, and then assist industries, government, academia, and research organizations to initiate the scientific research governance model and innovative thinking. ${ }^{(11)}$

The existing literature on the IoT rarely discusses the corporate value of the IoT industry or the upstream-downstream structure of industry. Therefore, in this study, we use the Ohlson model to analyze the profitability, book value, and other financial factors of the IoT industry companies in China and Taiwan in terms of the IoT concept stocks of the MONEY DJ wealth management network. Taiwanese companies in the IoT industry have a significant effect on the upstream, whereas Chinese companies and cross-strait companies have significant effects on the upstream and midstream. Driven by policies that master the IoT of core technologies and applications in various industries, China's IoT industry has gradually shown the effects of industrial hierarchy. ${ }^{(12)}$ In the era of IoT, creative marketing combined with information and mobile communication platforms has resulted in numerous interactive consumption patterns of online search, selection, and purchase or consumption. The main concept is to achieve effective distribution to meet demand goals under appropriate total transportation profits with different suppliers in a highly competitive environment. Therefore, sensitivity analysis is carried out using the tools of transportation theory and linear programming, and it is found that if the industry can effectively integrate, distribute, and share information, it will ensure product quality and shorten the waiting time of consumers, which can not only ensure or improve customer satisfaction, but also increase or create an industry-sharing economy. ${ }^{(13)}$

We propose the positioning analysis of the IoT system service industry and use it as a business opportunity service model to match the viewpoints of production, learning, and studies. We analyze and summarize the perspective of cutting into the IoT service industry; then, we look for service value activities in the IoT system service industry and propose business strategies for the future development of each service model in the future. In addition to formulating relevant laws and regulations and maintaining the order of industry for the government, we should also adopt appropriate awarding measures, provide good incentives, and encourage enterprises to invest actively. Telecom operators should take the initiative to provide potential and innovative advanced technology service platforms, and system integrators or service providers need to flexibly develop different business or service platforms based on the diversity of the future. Software and hardware integrators can build multi-functional intelligent terminal systems and construct more humanized virtual platforms and application stores through close cooperation. ${ }^{(14)}$ 


\subsection{Relationship between CDS and bonds}

Many international scholars use the CDS spread to discuss the credit risk of countries or enterprises. The most typical CDS transaction method is negotiation in accordance with the CDS spread through a contract between two parties. The buyer periodically pays the seller with the premium (capital multiplied by the credit spread). The seller provides credit guarantee. When a credit event defined in the contract occurs within the specified period, the buyer's losses must be made up in accordance with the terms of the contract.

Obviously, the factor of the CDS spread depends on the debtor's PD. Chan-Lau ${ }^{(15)}$ and Neftci et al. ${ }^{(16)}$ used the CDS spread to predict sovereign risk. In addition, Remolona et al. ${ }^{(17)}$ also used the CDS spread to estimate the sovereign risk premium, but because of the limitation of data, they could not directly obtain the CDS spread necessary for relevant analysis. Hull et al. ${ }^{(18)}$ and Chan-Lau ${ }^{(19)}$ discussed the relationship between the CDS spread and bond yield and indirectly used the PD estimated using the bond prices to calculate the CDS spread.

\subsection{Sovereign credit risk}

Sovereign credit risk has been a topic of great concern in recent years. Remolona et al. ${ }^{(20)}$ showed that the sovereign default risk is partially composed of sovereign spreads. The research of Remolona's group ${ }^{(21)}$ is aimed at distinguishing between the risk of sovereign credit spread and the risk premium. According to the related literature about corporate risk pricing, they divide the sovereign CDS spreads into sovereign default risk, and then calculate the expected loss and residual market premium based on the historical default rate of the sovereign rating agency. Remolona's group ${ }^{(21)}$ established a ratings-implied expected loss (RIEL), which is consistent with the rating company's evaluation and can be used for data rating.

\section{Research Methodology}

In this research, we use the data set for the 12 countries specified in the ROC Government's New Southbound Policy from 2006 to 2015 and then verify whether the effects of the CDS spread, macroeconomic variables, and the RIEL are consistent with the impact of only the macroeconomic variables.

\subsection{Estimation of CDS spread}

It was mentioned that owing to the limitation of data, it is impossible to directly obtain the data of the CDS spread. The CDS spread is calculated as

$$
S=\left(\frac{P D(1-R R)}{(1+r)}\right),
$$


where $P D$ represents the PD of the CDS spread, $R R$ represents the expected recovery rate after a default occurs, $r$ represents the risk-free interest rate of individual markets, and $S$ represents the credit default spread. However, under the assumption of frictionless capital markets, that is, fair pricing and risk neutrality, the CDS spread should be the same as the present value of the expected loss.

$P D$ can be obtained by ${ }^{(19)}$

$$
B=\frac{(1-P D)+P D \cdot R R}{1+d},
$$

where $P D$ represents the default probability of bonds, $R R$ represents a fixed recovery rate, $d$ represents the risk-free discount rate, and $B$ represents the present value of zero-coupon bonds. Then, Eq. (2) can be rewritten as

$$
P D=\frac{1-B(1+d)}{1-R R} .
$$

Duffie and Singleton ${ }^{(22)}$ and Hull and White ${ }^{(23)}$ confirmed that the bond price can be used as the yield spread of government bonds; as long as the spread is correct and there is no arbitrage, the bond spread can be used to estimate the $P D$. Therefore, in this study, we will use the $P D$ of the bond information to calculate the CDS spread.

\subsection{RIEL}

Remolona et al. ${ }^{(17)}$ used the relevant information of the credit rating agencies to construct a method of estimating RIEL. Moody's publishes individual average cumulative default rates for corporate and sovereign debts through various investment-level ratings. Their model is that for each country $(i)$ to accumulate a default rate of 5 years $\left(P D_{i}\right)$; assuming that the default frequency during this five-year period is fixed, the annualized value is $\delta_{i}$. ${ }^{(24)}$

$$
1-P D_{i}=A e^{-5 \delta_{i}} \Rightarrow \delta_{i}=-\frac{\ln \left(1-P D_{i}\right)}{5}
$$

Then, substituting each of RIEL into Eq. (4) and using the relationships among $E L, P D_{i}$, loss given default (LGD), and recovery rate (RR), we rewrite Eq. (4) as

$$
\begin{aligned}
R I E L_{i, t} & =-\frac{\ln \left(1-E L_{i, t}\right)}{5} \\
& =-\frac{\ln \left(1-P D_{i, t}(\overline{L G D})\right)}{5} \\
& =-\frac{\ln \left(1-P D_{i, t}(1-\overline{R R})\right)}{5} .
\end{aligned}
$$


Table 2

Moody's cumulative PD (unit, \%; Moody's 2016 Annual Report).

\begin{tabular}{lcccccccccc}
\hline Sovereign issuers & & & & & & & & & \\
\hline $\begin{array}{l}\text { Broad rating } \\
\text { category }\end{array}$ & Year 1 & Year 2 & Year 3 & Year 4 & Year 5 & Year 6 & Year 7 & Year 8 & Year 9 & Year 10 \\
\hline Aaa & 0.00 & 0.00 & 0.00 & 0.00 & 0.00 & 0.00 & 0.00 & 0.00 & 0.00 & 0.00 \\
$\mathrm{Aa}$ & 0.00 & 0.00 & 0.00 & 0.00 & 0.00 & 0.00 & 0.00 & 0.00 & 0.00 & 0.00 \\
$\mathrm{~A}$ & 0.00 & 0.00 & 0.00 & 0.00 & 0.00 & 0.00 & 0.00 & 0.00 & 0.00 & 0.00 \\
$\mathrm{Baa}$ & 0.00 & 1.66 & 2.61 & 3.70 & 5.08 & 6.91 & 6.91 & 6.91 & 6.91 & 6.91 \\
$\mathrm{Ba}$ & 0.57 & 1.20 & 2.58 & 4.90 & 4.90 & 4.90 & 6.22 & 7.90 & 10.20 & 13.30 \\
$\mathrm{~B}$ & 4.35 & 7.32 & 9.57 & 10.92 & 14.16 & 18.34 & 21.26 & 25.64 & 31.36 & 38.22 \\
Caa-C & 18.18 & 28.41 & 28.41 & 28.41 & 28.41 & 28.41 & $\mathrm{NA}$ & $\mathrm{NA}$ & $\mathrm{NA}$ & NA \\
\hline Investment grade & 0.00 & 0.31 & 0.48 & 0.67 & 0.89 & 1.14 & 1.14 & 1.14 & 1.14 & 1.14 \\
Speculative grade & 2.67 & 4.51 & 6.16 & 8.06 & 9.18 & 10.52 & 12.28 & 14.65 & 17.87 & 22.08 \\
\hline All sovereigns & 0.79 & 1.55 & 2.16 & 2.85 & 3.31 & 3.86 & 4.29 & 4.80 & 5.40 & 6.10 \\
\hline
\end{tabular}

Table 3

Moody's RR (Moody's 2016 Annual Report).

\begin{tabular}{lccc}
\hline 2012 & Belize & 40 & 65 \\
2013 & Cyprus & NA & 53 \\
2013 & Jamaica & NA & 89 \\
2014 & Argentina & 68 & 95 \\
2015 & Ukraine & 80 & NA \\
\hline Issuer-weighted recovery rate & & & 65 \\
\hline Value-weighted recovery rate & & & 46 \\
\hline
\end{tabular}

$P D$ and $R R$ applied in Eq. (5) were taken directly from Moody's annual report and are shown in Tables 2 and 3 (this figure is only the $P D$ in one of the years). The estimated CDS spread and RIEL for each country are plotted with time, as shown in Fig 1.

\section{Research Results and Findings}

\subsection{Panel data model}

After confirming that all variables are stationary, the one-dimensional model of panel data can be constructed as follows:

$$
Y_{i, t}=a_{0 i}+a_{1} F_{i, t}+\mu_{i, t},
$$

$Y_{i, t}: i$ country, dependent variable in year $t$

$F_{i, t}: i$ country, matrix collection of independent variables in year $t$;

$\mu_{i, t}: i$ country, error term in year $t$.

$Y_{i, t}$ is a variable dependent on CDS spread and RIEL. $F_{i, t}$ is an estimated independent variable and represents one of the five macroeconomic variables: gross domestic product growth (GDPG) rate, ratio of the current account balance (CAB) to the gross domestic product, industrial production index annual growth rate (IPIG), inflation rate (INF), and debt/GDP (DEBT). 


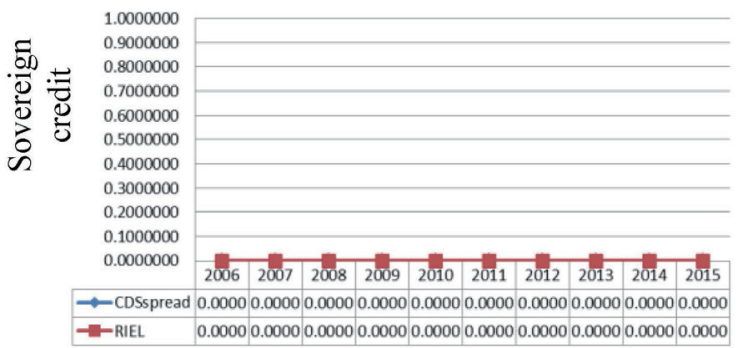

(a)

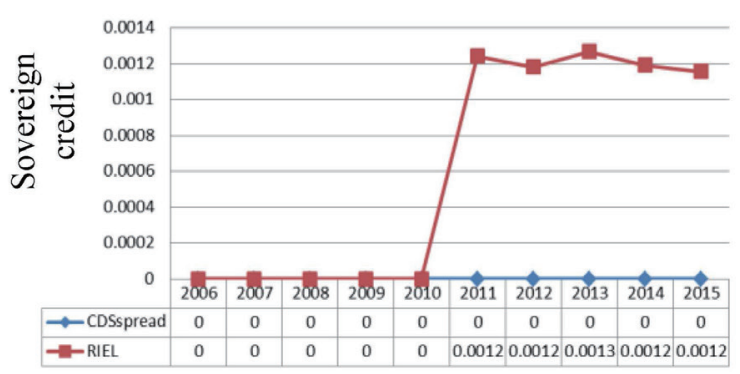

(c)

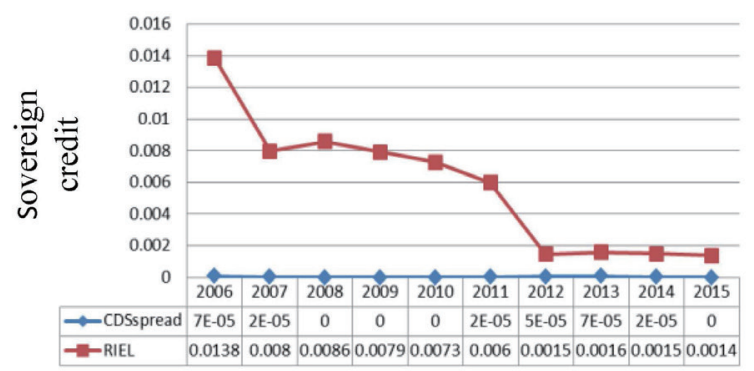

(b)

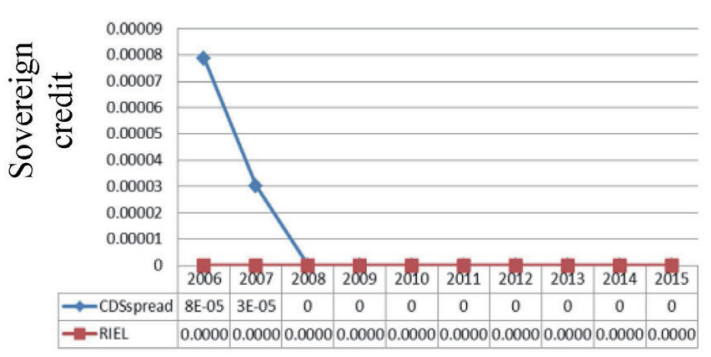

(d)

Fig. 1. (Color online) Sovereign risk of four counties. (a) Australia, (b) Indonesia, (c) Malaysia, and (d) New Zealand.

The above basic panel data model can be divided into the fixed effect model and the random effect model. These two models are based on individual effects and whether there is endogeneity between independent variables. In other words, the difference between the two models is that the structure represented by the intercept term is different. There is a correlation (endogenous) between the intercept term and the independent variable of the fixed effect model, that is, $\operatorname{cov}\left(F_{i, t}, a_{0 i}\right) \neq 0$. There is no correlation between the intercept term and the independent variable of the random effect model (exogenous), that is, $\left(F_{i, t}, a_{0 i}\right)=0$. Therefore, the random effect model is also the error component model.

\subsubsection{Fixed effect model}

The fixed effect model allows for differences between the variables in the model. The intercept term in this model is a fixed constant that can indicate the difference in the nature of each economic entity without being affected by time changes. This model uses dummy variables to show the difference in the properties of various economies. Therefore, the fixed effect model can also be called the dummy square model (least squares dummy variable model). The model is described as

$$
Y_{i, t}=\sum_{j=1}^{N} a_{j} D_{i, j}+\beta F_{i, t}+\varepsilon_{i, t},
$$


$Y_{i, t}: i$ country, dependent variable in year $t$;

$F_{i, t}: i$ country, matrix collection of independent variables in year $t$;

$\varepsilon_{i, t}: i$ country, error term in year $t$;

$D_{i, j}$ : intercept term for each cross section; when $i=j, D_{i, j}=1$ and when $i \neq j, D_{i, j}=0$.

From the results in Table 4, we know that under the model of the least squares method, INF, regardless of the significant level of $1 \%$ of the CDS spread or $5 \%$ of RIEL, has a significant effect. In addition, $\mathrm{CAB}$ has a significant impact at the significant level of $10 \%$ of RIEL. Other variables have no significant effect on the dependent variable.

The results in Table 5 show that in the fixed effect model, only INF has a significant effect at a significant level of $1 \%$ of the CDS spread. Other variables have no significant effect on the

Table 4

Regression analysis by least squares method.

\begin{tabular}{lcccc}
\hline \multicolumn{3}{c}{ Least squares method } \\
\hline Variable & Coefficient & T Statistics & Coefficient & RIEL \\
\hline C & $-2.71 \mathrm{E}-05$ & -0.885916 & -0.004609 & $1.879187^{*}$ \\
GDPG (\%) & $-9.61 \mathrm{E}-06$ & -1.386556 & -0.000179 & -0.320915 \\
CAB (\%) & $-1.49 \mathrm{E}-07$ & -0.100133 & -0.000215 & $-1.793713^{*}$ \\
IPIG (\%) & $3.47 \mathrm{E}-06$ & 0.958323 & 0.000064 & 0.219708 \\
INF (\%) & $2.10 \mathrm{E}-05$ & $8.388811^{* * *}$ & 0.000494 & $2.457817^{* *}$ \\
DEBT (\%) & $4.45 \mathrm{E}-05$ & 0.287176 & -0.011405 & -0.916434 \\
\hline R2 & 0.450811 & & 0.141110 & \\
Adj. R2 & 0.423890 & & 0.099008 & \\
F Statistics & $16.74570^{* * *}$ & $3.351592^{* * *}$ & \\
\hline
\end{tabular}

The variable codes are CDS spread, RIEL, GDPG rate, ratio of CAB, IPIG, INF, and ratio of DEBT.

NOTE: ${ }^{* * *}$ significant level of $1 \%,{ }^{* *}$ significant level of $5 \%,{ }^{*}$ significant level of $10 \%$.

Table 5

Regression analysis by fixed effect model.

\begin{tabular}{lcccc}
\hline \multicolumn{3}{c}{ Fixed effect model } \\
\hline Variable & Coefficient & T Statistics & Coefficient & RIEL \\
\hline C & $-3.44 \mathrm{E}-05$ & -1.003737 & 0.006837 & $3.193930^{* * *}$ \\
GDPG (\%) & $-2.73 \mathrm{E}-06$ & -0.370648 & 0.000257 & 0.560598 \\
CBA (\%) & $-3.18 \mathrm{E}-06$ & -0.982780 & 0.000204 & 1.010223 \\
IPIG (\%) & $1.77 \mathrm{E}-06$ & 0.507106 & -0.00206 & -0.942677 \\
INF (\%) & $1.78 \mathrm{E}-05$ & $6.514054^{* * *}$ & -0.000164 & -0.959946 \\
DEBT (\%) & $4.24 \mathrm{E}-05$ & 0.258368 & -0.005888 & -0.574603 \\
\hline R2 & 0.597090 & & 0.619159 & \\
Adj. R2 & 0.526249 & & 0.552198 & \\
F Statistics & $8.428563^{* * *}$ & & $9.246561^{* * *}$ &
\end{tabular}

The variable codes are CDS spread, RIEL, GDPG rate, ratio of CAB, IPIG, INF, and ratio of DEBT.

NOTE: ${ }^{* * *}$ significant level of $1 \%,{ }^{* *}$ significant level of $5 \%,{ }^{*}$ significant level of $10 \%$. 
credit default premium difference. In addition, all variables have no significant effect on the expected loss of ratings.

Because the results of the least squares method and the fixed effect model for the tracking data are very different, the suitability and interpretation ability of the models must be determined by verification. The F-test of the results of the least squares method reveals that the null hypothesis is rejected at the $1 \%$ level of significance, indicating that the fixed effect model may be more suitable than the least squares method.

\subsubsection{Random effect model}

As mentioned in the introduction of the fixed effect model, the intercept term of the fixed effect model is a fixed constant, which can indicate the difference between the properties of various economic entities without being affected by the change of time. However, this may ignore the time series (vertical section) of the possible impact. Therefore, in the random effect model, it is assumed that the error term of the period intercept term is a random variable. Moreover, the effect of the difference between the study data and the time series is presented on the error term $\mu_{i}$, so the random effect model can also be called the Error Component Model, which is as follows:

$$
Y_{i, t}=\left(\alpha+\mu_{i}\right)+\beta F_{i, t}+\varepsilon_{i, t}
$$

$Y_{i, t}: i$ country, dependent variable in year $t$

$F_{i, t}: i$ country, matrix collection of independent variables in year $t$;

$\varepsilon_{i, t}: i$ country, error term in year $t$;

$\mu_{i}$ : random variables generated for individual intercept terms.

The coefficients are shown in Table 6. From the results of the above table, we can see that in the random effect model for panel data, INF has a significant impact on the CDS spread, and the relationship between the two variables is positive.

Table 6

Coefficients of random effect model.

\begin{tabular}{lcc}
\hline & CDS spread & RIEL \\
\hline Variable & Coefficient & Coefficient \\
\hline C & $-3.26 \mathrm{E}-05$ & 0.005817 \\
GDPG (\%) & $-5.07 \mathrm{E}-06$ & 0.000221 \\
CBA (\%) & $-1.27 \mathrm{E}-06$ & -0.000135 \\
IPIG (\%) & $2.36 \mathrm{E}-06$ & -0.000143 \\
INF (\%) & $1.89 \mathrm{E}-05^{* * *}$ & 0.0000499 \\
DEBT (\%) & $4.40 \mathrm{E}-05$ & -0.007385 \\
\hline
\end{tabular}

The variable codes are CDS spread, ratings-implied expected loss (RIEL), GDPG rate, ratio of CAB, IPIG, INF, and ratio of DEBT.

NOTE: ${ }^{* * *}$ significant level of $1 \%,{ }^{* *}$ significant level of $5 \%,{ }^{*}$ significant level of $10 \%$. 


\subsubsection{Hausman test}

The panel data is divided into a fixed effect model and a random effect model, but the suitability of the models still requires the verification of the intercept term and the independent variable in the random effect model by the Hausman test

The null hypothesis of the Hausman test is that individual effects have no effect on independent variables, which means that a random effect model must be used; the alternative hypothesis is that individual effects are related to independent variables, which means that a fixed effect model must be used.

$$
\begin{aligned}
& H_{0}: E\left(\mu_{i}, X_{i, t}\right)=0 \\
& H_{1}: E\left(\mu_{i}, X_{i, t}\right) \neq 0
\end{aligned}
$$

If the test result contradicts the null hypothesis that $p$-value $<\alpha$, the assumption that individual effects are independent of the independent variables is not true, so the model selected should be a fixed effect model; otherwise, if the test supports the null hypothesis that $p$-value $>\alpha$, then the assumption that individual effects are related to independent variables holds, so the random effects model should be selected.

The Hausman test statistics are

$$
H=\left(\beta_{\text {fixed }}-\beta_{\text {random }}\right)^{T}\left[\operatorname{Var}\left(\beta_{\text {fixed }}\right)-\operatorname{Var}\left(\beta_{\text {random }}\right)\right]^{-1}\left(\beta_{\text {fixed }}-\beta_{\text {random }}\right) .
$$

$\beta_{\text {fixed }}$ : estimated value under fixed effect model,

$\beta_{\text {random }}$ : estimated value under random effects model.

After confirming the model using the panel data, it is necessary to judge whether the fixed effect model or the random effect model would be suitable for this study. The test for this determination is the Hausman test, and the test results are shown in Table 7.

The results in Table 7 show that the $p$-value of the Hausman test is 0.5870 , which does not contradict the null hypothesis, so the analysis model suitable for this study is the random effect model of tracking data. The DEBT does not have a significant impact on the CDS spread in this result, which is different from the predictions for previous variables. The direction of influence is consistent.

Table 7

Results of Hausman test.

\begin{tabular}{lccc}
\hline Null hypothesis: Individual effects have nothing to do with variables (random effect model) & \\
\hline & Chi-square statistics & $\begin{array}{c}\text { Chi-square degree } \\
\text { of freedom }\end{array}$ & $p$-value \\
\hline Fixed effect model vs Random effect model & 3.743047 & 5 & 0.5870 \\
\hline
\end{tabular}




\subsection{Unit root test of panel data}

The data period of this study is 10 years for 12 countries. This is the same as for the data proposed by Baltagi ${ }^{(25)}$ with a long time interval (between $25-250$ time intervals) and a small country sample (between 10-250 countries) or a short time interval and a large country sample database. Hence, the unit root test of Levin, Lin and Chu (LLC) is used. ${ }^{(26)}$ The LLC unit root test considers both time series (vertical-section) data and transnational (cross-sectional) data, which allows it to solve and overcome the problem of too few samples in the traditional unit root test, on the generalization of the augmented Dickey-Fuller test (ADF test). However, the LLC unit root test has more stringent restrictions, such as the time series of each group must have the same autoregression, indicating that the coefficients of the regression formulas for each country (cross-sections) must be homogeneous. When the sequence stability between the groups is different, the LLC unit root test cannot be used, so in this study, we simultaneously adopt the Fisher unit root test, presented by Maddala and $\mathrm{Wu},{ }^{(27)}$ that is more accurate than the LLC unit root test.

\subsubsection{LLC unit root test}

The panel unit root test proposed by Levin et al. ${ }^{(26)}$ is an improvement over the ADF unit root test in which the type of panel data is insufficient. The premise of LLC's unit root is that individual cross-sectional data (data from each country) have the same unit root.

The model and assumptions are as follows:

$$
\Delta y_{i, t}=\alpha_{i}+\beta_{i} y_{i, t-1}+\gamma_{i} t+\sum_{j=1}^{p} \theta_{i, j} \Delta y_{i, t-j}+\varepsilon_{i, t},
$$

where $i=1,2,3, \ldots, N, j=1,2,3, \ldots, T, \theta_{i, j}$ is the coefficient of the lagging number, and $p$ is the lagging order of the cross-sectional data (transnational data). Assuming that $\varepsilon_{i, t}$ is the distribution of the mean 0 and the variation is $\sigma^{2}$, the null hypothesis of the LLC unit root test is that the variable has a unit root, that is, the variable is nonstationary. In contrast, the alternative hypothesis does not have a unit root and the coefficient of the sequence per tissue is constant, that is, its variable is stationary.

$$
\begin{aligned}
& H_{0}: \beta_{1}=\beta_{2}=\beta_{3}=\cdots=\beta_{n}=\beta=0 \\
& H_{1}: \beta_{1}=\beta_{2}=\beta_{3}=\cdots=\beta_{n}=\beta<0
\end{aligned}
$$

If the test result rejects the null hypothesis that $p$-value $<\alpha$, then the hypothesis that the variable has a unit root is not true, and the variable is stationary; otherwise, if the null hypothesis is not rejected, that is, $p$-value $>\alpha$, the variable is nonstationary. Some variables determined to be nonstationary after verification need to be differentiated to achieve the state of the variable. 
The test statistics of the LLC unit root test are

$$
t_{\beta_{i}}=-\frac{\hat{\beta}_{i}}{\sqrt{\operatorname{Var}\left(\hat{\beta}_{i}\right)}} .
$$

$\hat{\beta}_{i}$ : least-squares estimate of $\beta_{i}$

$\operatorname{Var}\left(\hat{\beta}_{i}\right)$ : variation of $\hat{\beta}_{i}$

When the number of samples is sufficiently large, the test statistics of the LLC unit root test will approach the standard normal distribution.

\subsubsection{Fisher unit root test}

The Fisher unit root test is designed with a nonparametric form and combines various independent unit root tests. The null hypothesis of the Fisher unit root test is that the variable has a unit root, meaning that its variable is nonstationary; the alternative hypothesis is that the variable has no unit root, but there is at least one sequence whose coefficients are constant, which means that their variables are stationary.

$$
H_{0}: \beta_{1}=\beta_{2}=\beta_{3}=\cdots=\beta_{n}=\beta=0
$$

$H_{1}: \beta_{i}<0$ at least one sequence whose coefficients are constant

Like the LLC unit root test, if the test result rejects the null hypothesis that $p$-value $<\alpha$, the hypothesis that the variable has a unit root is not true, so the variable is stationary; otherwise, if the test does not reject the null hypothesis, $p$-value $>\alpha$, the assumption that the variable has a unit root holds and the variable is nonstationary. Variables determined to be nonstationary after verification must be differentiated to achieve the state of the variable.

The test statistics of the Fisher unit root test are

$$
\lambda=-2 \sum \ln \left(\pi_{i}\right) .
$$

The statistics are subject to chi-square distribution, and the Fisher unit root test can be divided into the PP-Fisher test and the ADF-Fisher test. Both tests are based on individual original tests, and each variable panel data unit root test is performed to obtain higher verification power.

The test results of the unit root test are shown in Table 8 below. As can be seen from the test statistics in the table, when the LLC unit root test is at a significant level of $1 \%$, all variables can reject the null hypothesis, that is, all variables are in the steady state. The Fisher unit root test can reject the null hypothesis (reject H0) at a significant level of 1\%, except for RIEL and DEBT, so the above five variables, GDPG, CBA, IPIG, INF, and DEBT, are all stationary. The results can reject the null hypothesis, except for RIEL, at a significant level of $1 \%$, and further, can reject the null hypothesis at a significant level of $5 \%$, so all variables are stationary. 
Table 8

Panel data unit root test.

\begin{tabular}{llcc}
\hline \multicolumn{3}{c}{ Null hypothesis: unit root (variables are nonstationary) } \\
\hline & Test statistics & LLC unit root test & Fisher unit root test \\
\hline & CDS spread & T Statistics & T Statistics \\
& RIEL & $-13.6199^{* * *}$ & $35.5108^{* * *}$ \\
& GDPG (\%) & $-3.58730^{* * *}$ & $30.9338^{* *}$ \\
Origin & CAB (\%) & $-10.9492^{* * *}$ & $78.3441^{* * *}$ \\
& IPIG (\%) & $-6.24346^{* * *}$ & $52.2230^{* * *}$ \\
& INF (\%) & $-7.92369^{* * *}$ & $69.8724^{* * *}$ \\
& DEBT (\%) & $-6.93109^{* * *}$ & $62.5393^{* * *}$ \\
\hline First-order difference & DEBT (\%) & $-4.6174^{* * *}$ & 29.8669 \\
\hline
\end{tabular}

The variable codes are CDS spread, RIEL, GDPG rate, ratio of CAB, IPIG, INF, and ratio of DEBT.

NOTE: ${ }^{* * *}$ significant level of $1 \%,{ }^{* *}$ significant level of $5 \%$.

The purpose of this study was to analyze the relationship between the CDS spread and the overall economic indicators, and then to explore whether this can be used to judge the basis of sovereign credit risk. However, among the indicators of the overall economy, we selected five, GDPG, CAB, IPIG, INF, and DEBT, as the independent variables discussed in this study and used them to analyze the 12 countries in the ROC Government's New Southbound Policy using the panel data model.

\section{Conclusions}

Based on the results of the empirical analysis in the previous sections, under the ordinary least squares method, the correlation between the respective variables and the CDS spread is in the negative direction of the GDPG rate. The negative relationship of the CAB to the ratio of gross domestic production, the positive relationship of the annual increase rate of the IPIG to the CDS spread, and the positive relationship of the INF to the CDS spread are the same as each variable and the expected loss of the rating. However, the ratio of government DEBT and the CDS spread is positively correlated. Therefore, the results of these studies and the RIEL are the same as the results of the relevant analysis from these five overall economic indicators. Therefore, the establishment of a big data database system for the IoT through real-time sensing technology and big data analysis of national data indicators can effectively improve the assessment of investment risks.

As can be inferred from the results of this study, in the increasingly complex environment of the IoT, the global commercial market is growing rapidly under the application of sensing technology and IoT technology (such as cloud computing, mobile devices, and wireless networks). In the face of rapid changes in the IoT environment and technological innovation, the big data investment risk indicator and the timely prediction and analysis of financial data based on the principle of the IoT will enable investors to receive timely warnings to reduce investment risk. 


\section{References}

1 W. J. Wang: Econ. Outlook Bimonthly 168 (2016) 29.

2 J. Y. Ye: Taiwan Econ. Res. Mon. 42 (2019) 101. https://doi.org/10.29656/TERM.201910_42(10).0014

3 K. Y. Deng and Y. Syu: Ind. Des. 131 (2015) 26.

4 S. W. J. Hang: Account. Res. Mon. 357 (2015) 76. https://doi.org/10.6650/ARM.2015.357.76

5 H. F. Lin, R. Y. Chung, and T. Y. Wang: J. Contemp. Bus. Manage. 2 (2017) 24. https://doi.org/10.6852/ JCBM.201712 2.0002

6 J. Liang: Insur. Monogr. 31 (2015) 125.

7 J. D. Novak and D. B. Gowin: Learning How to Learn (Cambridge University Press, 1984). ISBN: 0521319269

8 J. Landet: J. Technol. Forecast. Soc. Change 73 (2006) 467. https://doi.org/10.1016/j.techfore.2005.09.002

9 D. Dickins and R. G. Fay: Am. Account. Assoc. 32 (2017) 117. https://doi.org/10.2308/iace-51585

10 S. I. Chang, L. M. Chang, G. Wan, and J. C. Liao: J. Electron. Bus. 21 (2019) 77. https://doi.org/10.6188/ JEB.201906 21.0003

11 C. C. Lin and S. H. Chen: Econ. Outlook Bimonthly 188 (2020) 78.

12 C. F. Ko and C. H. Chang: Soochow J. Econ. Bus. 95 (2017) 57.

13 H. L. Hai, K. M. Wang, J. J. Niu, A. C. Liu, F. Y. Zhong, and W. H. Song: Manage. Inf. Comput. 6 (2017) 76. https://doi.org/10.6285/MIC.6.06

14 K. C. Lin, J. S. Wang, C. C. Peng, and J. Z. Shyu: J. Technol. Manage. 19 (2014) 51.

15 J. A. Chan-Lau: 2003 IMF WP. 03rd 106-126.

16 S. Neftci, A. O. Santos, and Y. Lu: CUNY WP (2005).

17 E. M. Remolona, M. Scatigna, and E. Wu: J. Fixed Income 17 (2008) 57. https://doi.org/10.3905/jfi.2008.705542

18 J. Hull, M. Predescu, and A. White: J. Bank Financ. 28 (2004) 2789. https://doi.org/10.1016/j. jbankfin.2004.06.010.

19 J. A. Chan-Lau: 2006 IMF WP 06th 104-123.

20 E. M. Remolona, M. Scatigna, and E. Wu: BIS Q. Rev. (2007).

21 E. M. Remolona, M. Scatigna, and E. Wu: Int. J. Finance Econ. 13 (2008) 26. https://doi.org/10.2139/ ssrn.963041

22 D. Duffie and K. Singleton: Rev. Finance Stud. 12 (1999) 687. https://doi.org/10.1093/rfs/12.4.687

23 J. C. Hull and A. White: J. Deriv. 8 (2000) 29. https://doi.org/10.3905/jod.2000.319115

24 D. Darrell and J. S. Kenneth: Credit Risk: Pricing, Measurement, and Management (Princeton University Press, 2003). ISBN 10: 0691090467

25 B. H. Baltagi: Econometric Analysis of Panel Data (John Wiley \& Sons, Inc., 2005) 3rd ed.

26 A. Levin, C. F. Lin, and C. S. J. Chu: J. Econ. 108 (2002) 1. https://doi.org/10.1016/S0304-4076(01)00098-7

27 G. S. Maddala and S. Wu: Oxford Bull. Econ. Stat. 61 (1999) 631. https://doi.org/10.1111/1468-0084.0610s1631 